\title{
As crianças e a guerra, pela voz de um pedagogo da Escola Nova em Portugal
}

\author{
(Children and war through the eyes of a pedagogue \\ of the progressive education movement in Portugal)
}

\author{
Carlota BOTO \\ Faculdade de Educação da Universidade de São Paulo
}

\begin{abstract}
RESUMO: António de Sena Faria de Vasconcelos (1880-1939) é um pedagogo português e proeminente educador representante da Escola Nova em Portugal. Destacou-se no desenvolvimento do pensamento pedagógico contemporâneo, a partir da sua atuação na Universidade Nova de Bruxelas e com a criação de uma escola em Bierges-Les-Wavre - experiência que ficou eternizada especialmente em Uma escola nova na Bélgica, publicado em 1915. Depois do início da Primeira Guerra, o autor se dirigirá a Genebra, passando a integrar a equipe que compunha na época o Instituto Jean-Jacques Rousseau. $O$ artigo aqui apresentado versa sobre uma conferência proferida na Suíça em abril de 1915, depois da publicação de Uma escola nova na Bélgica. O objetivo do trabalho é valorizar a correlação entre a situação da infância e a realidade da guerra, desvelando em simultâneo a compreensão da concepção de criança que norteava o pensamento de Faria de Vasconcelos. A metodologia para a abordagem do tema consiste numa análise do texto Les enfants et la guerre, em diálogo com 0 pensamento psicopedagógico vigente na época. $O$ desenvolvimento do conteúdo do artigo incidirá na verificação da relação das crianças com a guerra que, segundo Faria de Vasconcelos, era de pavor e de fascínio. Parte-se da originalidade da referida publicação para se pensar as questões da infância, bem como para problematizar o conceito de guerra. Como reflexões finais, constata-se a coerência entre os princípios da Escola Nova e essa abordagem inaudita acerca do vínculo entre as crianças e a guerra.
\end{abstract}

PALAVRAS-CHAVES: Faria de Vasconcelos; Escola Nova; História da Educação; infância; guerra.

ABSTRACT: António de Sena Faria de Vasconcelos (1880-1939) was a leading Portuguese pedagogue and a prominent representative of the progressive education movement in Portugal. He played an influential role in the development of the educational thinking of his time, most notably through his work at the New University of Brussels and the creation of a school

\footnotetext{
${ }^{1}$ Professora titular, leciona Filosofia da Educação. É Bolsista Produtividade PQ1D do CNPq. Integra o conjunto de pesquisadores principais do Projeto FAPESP 18/26699-4, intitulado Saberes e práticas em fronteiras: por uma história transnacional da educação.
} 
in Bierges-Les-Wavre, an experience he chronicled in the book, A New School in Belgium, published in 1915. When World War I broke out, he went to Geneva to join the team of educational scientists at the Jean-Jacques Rousseau Institute. This paper focuses on a lecture delivered by Faria de Vasconcelos in Switzerland in April 1915, following the publication of A New School in Belgium. The aim of the research is to examine the correlation established by the author between childhood and war, and to provide new insights into the conception of childhood that guided his thinking. The study analyses the text of his lecture, 'Les enfants et la guerre', in dialogue with the psycho-pedagogical thinking of the time. The analysis focuses on children's response to war, which Faria de Vasconcelos conceived of as one of fear and fascination, using his innovative perspective on the topic to reflect on ideas of childhood and to problematise the concept of war. The paper concludes with a reflection on the consistency of perspective between the principles of the progressive education movement and Faria de Vasconcelos's unique analysis of the link between childhood and war.

KEYWORDS: Faria de Vasconcelos; progressive education; history of education; childhood; war.

\section{Introdução}

António de Sena Faria de Vasconcelos (1880-1939) foi um importante educador português do início do século XX, representante do movimento da Educação Nova em Portugal. Atuou basicamente na Universidade Nova de Bruxelas e criou uma escola em Bierges-Les-Wavre -experiência que, posteriormente, originou a redação de Uma escola nova na Bélgica, publicado em 1915. Após o início da Primeira Guerra, o autor foi para Genebra, onde fez parte da equipe que compunha na época o Instituto JeanJacques Rousseau. Este artigo é sobre uma conferência proferida na Suíça em abril de 1915, depois da publicação de Uma escola nova na Bélgica. As finalidades do trabalho são a de apreender o tema exposto pelo autor na ocasião, a partir da intersecção entre a situação da infância e o fato da guerra. Pode-se averiguar, por meio de tal estratégia, a acepção de criança que norteava o pensamento de Faria de Vasconcelos. No tocante à metodologia do trabalho, o foco foi a análise do texto (compreendido aqui como fonte) Les enfants et la guerre. Tratar-se-á, sobretudo, de verificar como Faria de Vasconcelos compreendia a relação das crianças com a guerra; relação essa que, segundo o autor, era de pavor e de fascínio. A referida publicação é original e pode desvelar alguma perspectiva mediante a qual a situação da infância era interpretada à época. Pode também elucidar aspectos importantes do imaginário social e das representações coletivas acerca do conceito de guerra. Como reflexões finais, procurar-se-á encontrar as interações entre os princípios da Escola Nova e essa abordagem inusitada a respeito do vínculo entre as crianças e a guerra.

\section{Faria de Vasconcelos: um clássico da literatura pedagógica em Portugal}

Faria de Vasconcelos é já um autor bastante comentado pela literatura pedagógica portuguesa. Procuraremos a seguir trazer à tona uma parcela do debate protagonizado por sua referência, elencando autores e obras que se reportam à produção teórica do 
educador. Mais do que reconstituir a bibliografia sobre o tema, buscaremos evocar algum estado da arte.

Madalena Luzia Pereira Duarte recorda que, na transição entre os séculos XIX e XX, desenvolveu-se mundialmente um movimento de crítica à estrutura e ao funcionamento da escola tal como ela era. Passando a caracterizar esse modelo escolar como escola tradicional, criticava-se o fato de a instituição ser configurada sobre o papel do professor e das matérias de estudo, desconsiderando o aluno e seus interesses. Assim, surge uma nova proposta de escolarização, em um "ensino que devia ser centrado no aluno, nos seus interesses, respeitando as suas fases de desenvolvimento, o seu ritmo e as diferenças individuais, utilizando métodos ativos"2. Luís Alberto Marques Alves, por sua vez, indica os modos pelos quais esse movimento chegou praticamente ao mesmo tempo em Portugal e no Brasil.

Com Faria de Vasconcelos, a Educação Nova ou Escola Nova pretende estruturar-se como um "laboratório de pedagogia prática", como um sistema de coeducação dos sexos, de desenvolvimento do espírito crítico, por meio do que se supunha ser a aplicação de um método científico. Nesse sentido, é muito claro que as novas concepções de criança e de aluno, bem como de método de ensino e de matérias de estudo que presidiam as representações sobre a Escola Nova, eram absolutamente aliadas à crença de que se estaria aplicando um novo método científico, uma nova visão de conhecimento sobre a criança e sobre seu aprendizado. ${ }^{3}$

Justino Magalhães bem caracteriza os expoentes do movimento da Escola Nova em Portugal e no Brasil como intelectuais. Tratava-se, nos dois casos, da busca por uma escola republicana, a partir da ação coletiva e pública de sujeitos que atuam, agem e escrevem como intelectuais.

Como efeito, o contato com a escrita educacional, em qualquer grau, exige uma componente intelectiva. Não há educação exclusivamente prática ou praticista. Mas também os intelectuais sobrevivem, em boa parte, fazendo da educação a praça pública. O poder simbólico dos intelectuais legitima que tratem a educação como epistheme, instituição, ação. ${ }^{4}$

Jorge do Ó destaca que o discurso da Escola Nova contribui para transformar a criança em aluno. Trata-se, nesse sentido, de um movimento que tem antecedentes desde 0 princípio da construção da escola moderna, mas que agora ganha ares de cientificidade, mediante a construção de "uma miríade de instrumentos criados para apreciar, descrever,

\footnotetext{
${ }^{2}$ Madalena Luzia Pereira Duarte, À descoberta da Escola Nova de Faria de Vasconcelos (Dissertação de mestrado: Departamento de Educação da Universidade de Aveiro, 2010), 18.

${ }^{3}$ Luís Alberto Marques Alves, "República e educação: dos princípios da Escola Nova ao Manifesto dos Pioneiros da Educação", Revista da Faculdade de Letras - História 11 (2010): 169.

4 Justino Magalhães, "Intelectuais e história da educação em Portugal e no Brasil", Cadernos de História da Educação, 15 (1) (2016): 305.
} 
avaliar e comparar" ${ }^{\prime \prime}$. O que efetivamente mudava com a estruturação do discurso da Escola Nova?

Ora, a partir de finais do século XIX e para executar esta tarefa propriamente política, começou a ganhar corpo uma forma de saber positivo que associava políticos, professores, médicos, higienistas e demais experts da profilaxia social. A pedagogia adquiria o seu estatuto de ciência, de um lado, na crítica aos métodos autoritários da escola tradicional - que via todos os estudantes da classe como um só e se limitava ao básico ler, escrever e contar - e, de outro, na procura da educação integral do indivíduo tomado em si e para si. A Educação Nova - designação que na transição para o século XX identifica as tentativas de renovação pedagógica na Europa e nas Américas - alicerça-se no conhecimento detalhado da diferença de cada criança. Fala mesmo da lei da individualidade, querendo por tal significar que todo o indivíduo difere mais ou menos, na relação dos seus caracteres físicos e psicológicos dos demais. É, pois, esta uma ciência do singular que, legitimada pelo laboratório e pela observação experimental, postula a necessidade de uma escola por medida. ${ }^{6}$

António Nóvoa também enfatiza o propósito nitidamente científico dos arautos do movimento da Educação Nova em Portugal, particularmente expresso nos escritos de Faria de Vasconcelos. Não se trata, portanto, de apenas transferir para o aluno a primazia do processo educativo. É imprescindível que isso seja feito à luz das recomendações da ciência. A ideia era a de que a pedagogia deixasse de ter uma dimensão de vocação e passasse a ser ditada por preceitos cientificamente orientados. Para Nóvoa, os primeiros trabalhos de Faria de Vasconcelos foram pautados pela desconfiança e pela crença na educação escolar. Ao relatar especificamente a experiência da escola que dirigiu em Beirges-les-Wavre, no texto Uma escola nova na Bélgica,

Faria de Vasconcelos explica a criação da escola e apresenta os seus princípios orientadores, insistindo nos métodos de ensino que lhe concedem uma identidade própria. Depois de um século de teorias pedagógicas, importava, agora, explicar concretamente o que se fazia, esperando que esta ilustração fosse inspiradora a contribuísse para lançar a semente da Escola Nova (a metáfora da sementeira é, desde esta época, a que melhor caracteriza o discurso da inovação pedagógica). Era preciso passar das ideias às práticas e, ao mesmo tempo, transformar as práticas num laboratório de experimentação. ${ }^{7}$

Nesse sentido - como observa Carlos Meirelles-Coelho - , uma das grandes inovações foi a organização das turmas em classes móveis, nas quais os alunos eram reunidos conforme o preparo intelectual e o nível de conhecimento, com a possibilidade, inclusive, de "estar em níveis diferentes em cada área ou disciplina, havendo a preocupação de dar horas suplementares de aulas aos que vão mais devagar, podendo dar-se menos horas aos que vão mais depressa no respeito pelo ritmo individualizado de aprendizagem de cada aluno" ${ }^{8}$ Além disso, as matérias seriam agrupadas, de maneira a que houvesse uma

\footnotetext{
${ }^{5}$ Jorge do Ó, "A governamentalidade e a história da escola moderna: outras conexões investigativas", Educação \& Realidade 34(2) (2009): 114.

6 Ibidem.

${ }^{7}$ António Nóvoa, Evidentemente: histórias da educação (Porto: Asa, 2005), 57.

${ }^{8}$ Carlos Meirelles-Coelho, "Educação intelectual, moral e física segundo Faria de Vasconcelos", en Actas do Simpósio Internacional Activação do desenvolvimento psicológico (Aveiro: Universidade de Aveiro, s/d), 449.
} 
menor concentração de matérias por dia, com o fito de fazer com que as áreas de estudo fossem aprofundadas e melhor trabalhadas.

Joaquim Pintassilgo enfatiza o tema do self-government escolar como uma das experiências mais interessantes do movimento da Escola Nova em Portugal; e, em especial, do pensamento de Faria de Vasconcelos. $O$ pressuposto dessa prática era transformar a escola em uma sociedade em miniatura, no seio da qual as crianças seriam habituadas a exercitar a vida na cidade. Tratar-se-ia, nesse sentido, de procurar criar nos educandos uma forma de vivenciar sua condição em sociedade, com os direitos e os deveres que são a ela correlatos. Assim, era como se fossem replicadas "em ponto pequeno" todas as instituições do mundo adulto. Esse conceito de self-government foi bastante caro à produção teórica de Faria de Vasconcelos, nos mesmos anos em que ele escreve Les enfants e la guerre.

Ernesto Candeias Martins recorda que foi em julho de 1915 que, em prefácio a seu livro Uma escola nova na Bélgica, o pedagogo Ferrière atribuiu a Faria de Vasconcelos 0 epíteto de "pioneiro da educação do futuro". ${ }^{10} \mathrm{~A}$ ideia de Escola Nova era tomada como uma promessa, expressa, assim, no discurso e nos projetos de ação. Tal acepção de pioneiro marca uma palavra de honra e um significado, vindo exatamente de um dos principais expoentes mundiais do que ficou caracterizado como movimento da Escola Nova. Naquela época - como sublinha Teresa Sousa Machado - o mote da recém-fundada república portuguesa era o de inverter a "chaga social do analfabetismo", ${ }^{11}$ reformando a mentalidade portuguesa por meio da instrução e da educação. Acreditava-se que Portugal entrava no século XX com atraso relativamente aos demais países europeus e precisamente naquele ano de 1915, em que já teriam se feito sentir os efeitos da guerra, Faria de Vasconcelos colaborava com Claparède, Bovet e Ferrière no Instituto Jean-Jacques Rousseau em Genebra. Seria nesse ano que ele escreveria seu texto sobre as crianças e a guerra.

\section{Entre a pedagogia científica e a Educação Nova}

Faria de Vasconcelos destaca-se, já em seus primeiros trabalhos, por desenvolver a tese de que a criança constitui um "tanto física como psiquicamente um tipo especial que difere não só quantitativamente, mas qualitativamente do adulto". ${ }^{2}$ Ancorado pelos trabalhos de Rousseau, que dizia que a infância deve amadurecer nas crianças, Faria de Vasconcelos assinala a necessidade de tratar a criança como criança e não querer antecipar a ordem da natureza: "descer até ela, respeitá-la nas suas pretensas frivolidades

\footnotetext{
${ }^{9}$ Joaquim Pintassilgo, "Construção histórica da noção de democratização de ensino: o contributo do pensamento pedagógico português", en Democratização escolar: intenções e apropriações, org. Maria Manuel Vieira, Joaquim Pintassilgo y Bendita Melo (Lisboa: Centro de Investigação em Educação, 2003), 119-141.

${ }^{10}$ Ernesto Candeias Martins, "Faria de Vasconcelos, pioneiro da Educação Ativa: orientação escolar e profissional e o sistema educativo português", Imagens da Educação 5 (3) (2015): 71.

${ }^{11}$ Teresa Sousa Machado, "Faria de Vasconcelos: um pioneiro do movimento da Escola Nova na Europa e na América Latina", Revista Argentina de Ciencias del Comportamiento 8 (2) (2006): 115.

12 Faria de Vasconcelos, Obras completas, tomo I (Lisboa: Fundação Calouste Gulbenkian, 1986), 189.
} 
e ridicularias que, sem dúvida, representam a forma que reveste a satisfação das necessidades imprescindíveis do seu organismo". ${ }^{13}$

Em Lições de pedologia e pedagogia experimental, obra de 1909, Faria de Vasconcelos já destacava a necessidade de se proceder a um estudo científico da criança, indicando que isso compreenderia o estudo objetivo de sua natureza física e psíquica. Para o autor, o melhor professor seria aquele capaz de melhor conhecer seus alunos. A pedologia, por sua vez, era a ciência experimental da criança, uma ciência nova, que teria como base as observações metódicas sobre a vida infantil: "a pedologia abrange todos os problemas respeitantes à natureza física e psíquica da criança cuja solução procura no sentido de uma pedagogia prática, de uma educação natural e lógica da criança". ${ }^{14}$ Isso significava estudar os problemas concernentes ao crescimento da criança, ao estímulo de suas forças e aos fatores capazes de conduzir a criança à plenitude de seu potencial, especialmente à sua capacidade de aquisição de conhecimentos.

Ocorre que, nos estudos de Faria de Vasconcelos, essa vaga referência a Rousseau mescla-se a um claro vínculo com as ideias classificatórias de Binet, que se propunha a escrutinar a infância e a escolarização a partir de testes de medida. A criança, assim, torna-se um ser decifrável. A acepção de normalidade dá a tônica do discurso e a transformação da criança em aluno é pautada por tal aplicação de critérios do que pode ser considerado normal neste ou naquele comportamento infantil. Entretanto, a irrupção da guerra atrapalha toda essa teorização. Como lidar com esse binômio da criança na guerra? Esse é o desafio que se pretende enfrentar no presente trabalho.

\section{Crianças em tempos de guerra: do medo ao fascínio pelo combate}

O texto é Les enfants et la guerre. Nele, Faria de Vasconcelos inicia sua abordagem explicitando que o problema da guerra, relativamente à infância, poderia ser visto sob diversos pontos de vista: uma das perspectivas possíveis seria a compreensão das crianças como vítimas da guerra; outra dimensão seria o futuro dessa infância que enfrentou a problemática da guerra. $\mathrm{O}$ autor se pergunta o porquê de a guerra interessar tanto a crianças que, muitas vezes, querem entrar no combate. Seria razoável permitir às crianças a participação nas trincheiras da guerra? O lugar da criança não seria a escola? Como apresentar a guerra às crianças? Quais representações sociais sobre a guerra deverão constar dos relatos escolares? Além disso, haveria de se considerar os familiares das crianças que, tendo ido para 0 combate, voltavam machucados, mutilados, quando não eram mortos. Assim, a guerra seria um cenário de produção de órfãos. Órfãos não apenas de pais que morreram, mas órfãos, muitas vezes, da própria infância, que se teria perdido, no regresso de pais com desequilíbrio nervoso, com traumatismos físicos e problemas mentais.

Faria de Vasconcelos constata que se estaria a viver uma grande crise em nível mundial e que seria fundamental, naqueles anos da guerra, haver um especial esforço na proteção

${ }^{13}$ Ibidem, 190.

14 Ibidem, 206. 
da infância. A guerra já teria causado doenças, misérias e problemas profundos de toda a espécie. Proteger as crianças corresponderia, nesse sentido, a zelar pela vida social. Para o educador português, todas as medidas e todas as instituições que tinham "por missão preservar a evolução normal da criança" apresentavam, naquele momento, "um interesse capital". Se ainda antes da guerra havia, "em todos os países, obras, tanto privadas quanto públicas, bem como uma legislação social de proteção da infância", naquele período, nos países beligerantes, a máquina social tendia a funcionar quase exclusivamente para a guerra, pelo que muitas dessas medidas não eram aplicadas e muitas dessas instituições não funcionavam..$^{15}$

Faria de Vasconcelos classifica as obras da iniciativa privada criadas por instituições que visavam proteger e educar as crianças vítimas da guerra, em especial, os mutilados, órfãos e desvalidos. Considera, em primeiro lugar, que a obra de preservação da infância começava pela mãe: assistência moral, material e intelectual das mulheres grávidas "contra a miséria, as privações, os problemas, os medos, os desesperos que a partida, 0 desaparecimento ou a morte do esposo podem ocasionar". ${ }^{16}$ Assim, a preocupação em atender às necessidades das mulheres grávidas seria o primeiro cuidado recomendado em relação à infância. Mas, desde o momento em que a criança nasce, a carga social será, seguramente, redobrada, diz 0 autor. Será necessário, efetivamente, fazer com que a mãe volte à sua saúde normal e será imprescindível, ao mesmo tempo, favorecer o desenvolvimento do "pequeno ser". ${ }^{17}$ Os recursos e a seguridade da mulher que amamenta eram também tidos por fundamentais. Além disso, havia de se institucionalizar asilos maternais, creches, gotas de leite etc. Tais obras seriam tão mais relevantes quanto fosse elevada a mortalidade infantil.

Desde o início da guerra, no ano anterior, haviam nascido por volta de dez mil bebês nas imediações de Paris. Foi criado, na França, naquela ocasião, um comitê de Secours aux enfants du soldat, que solicitava da população o envio de produtos alimentares e de vestimentas destinadas às mães que amamentavam seus filhos. Citando as realidades da França e da Bélgica, Faria de Vasconcelos pontua inúmeras instituições que teriam sido criadas em outros países com o objetivo de proteger as crianças durante a vigência da guerra, discorrendo, em especial, sobre a Association des orphelins de la guerre em Paris. De fato - pondera 0 autor -, havia um significativo problema educativo a ser enfrentado por ocasião da guerra, que extravasava a proteção da criança. Como ele dizia: "trata-se de formar uma juventude numerosa, preservando o maior número possível de crianças das más condições habituais de seu meio social (vícios, doenças, misérias etc.) ou daquelas criadas ou agravadas pela guerra". ${ }^{18}$ Era, portanto, preciso também educar; era necessário que as crianças adquirissem as qualidades indispensáveis ao homem do pós-guerra, "encarregado de recriar as forças mutiladas e perdidas". Tendo isso em consideração, ele interroga-se sobre "as condições às quais a escola deve responder para formar uma juven-

\footnotetext{
15 Ibidem, 77.

${ }^{16}$ Ibidem.

17 Ibidem, 78.

${ }^{18}$ Faria de Vasconcelos, Obras completas, Tomo VII (Lisboa: Fundação Calouste Gulbenkian, 2011), 83.
} 
tude clarividente, enérgica, corajosa, consciente de suas responsabilidades". ${ }^{19} \mathrm{O}$ referido pedagogo tem consciência de que o problema não pode ser resolvido de um dia para 0 outro, em plena tormenta. Segundo ele, parecia que naquele período de angústia, de combates, de tempestade, apenas o presente é que contava. Diz ele exatamente:

O futuro é tão distante; não conseguimos discerni-lo do nevoeiro que tudo obscurece. Todas as forças tendem à realidade cotidiana, imperiosa, brutal, de onde deve surgir animado e vivo um mundo novo, com direitos invioláveis, pleno de justiça inatacável. Tudo isso nos escuta, nos aguarda e nos espera. Falar de instrução, de educação, quer dizer, de futuro, parece inoportuno. Como, de fato, encaminhar o menino para aquela posição difícil de estudar e de organizar os ruídos de futuro distantes, quase imperceptíveis, em uma sinfonia viva e clara, ele que é todo ouvidos aos barulhos dos canhões e aos tiros das metralhadoras? Porque a guerra interessa, apaixona, mobiliza a criança. Ela vive a guerra. Ela assume da guerra, em muitos casos, uma parte de bravura ativa. Mas sempre buscando dar a vocês as razões pelas quais a guerra interessa à criança, espero poder vos mostrar que 0 verdadeiro lugar da criança é a escola e que o trabalho escolar, sobretudo nessa hora, é para ela não somente uma necessidade fisiológica e psicológica, mas um dever social e humano. ${ }^{20}$

A tese fundamental defendida por Faria de Vasconcelos em seu texto é a de que a guerra não provoca apenas medo nas crianças. Ela provoca também fascínio. Mais precisamente, seria a partir dos oito anos que a guerra suscita na criança um conjunto de emoções, de sentimentos, de ideias que tangenciam o seu desenvolvimento intelectual e moral. Tais emoções, sentimentos e ideias tornar-se-iam progressivamente mais complexos, quanto mais avançada a idade da criança. Nesse sentido, poder-se-ia dizer - com 0 autor - que "a guerra satisfaz o sentimento de heroísmo da criança, cuja paixão pela glória, o prazer de combater, o gosto da ação, do espetáculo, o amor da liberdade, da aventura, o desejo ardente da fantasia, de jogar um papel, formam o fundo verdadeiramente humano". ${ }^{21}$ Essa atração da infância e da juventude pela guerra derivaria de mecanismos instintivos, primitivos, ancestrais... E as crianças agem com elementos de bravura e de sentimentos que são fogosos e impulsivos, muitas vezes até temerários. A perspectiva do educador era a de que o ser humano, desde a infância, no desenvolvimento de sua vida, percorreria individualmente as etapas que a espécie percorreu em sua caminhada histórica: "a criança revisita, evidentemente de uma maneira acelerada e fragmentária, as fases sucessivas pelas quais passou a humanidade". ${ }^{22}$ A partir de tal interpretação, faria parte do desenvolvimento psicofísico da infância, como se fosse consequência de uma lei natural, "esse estado de alma guerreiro, que ama o soldado, o herói, a ação, o combate". ${ }^{23}$

Quando a guerra foi declarada, a criança perdeu seu lugar de proteção e a família deixou de ser o refúgio de sua inocência. Mesmo assim, havia de se considerar a escola como o local adequado para preservar a infância. Mas quais seriam os métodos e os princípios da educação de uma escola em um tempo de guerra? Essa é a questão fundamental sobre a qual se debruçará o educador português. Ora, se é natural o prazer da guerra, o gosto

\footnotetext{
${ }^{19}$ Ibidem

${ }^{20}$ Ibidem, 83-4.

${ }^{21}$ Ibidem, 85.

${ }^{22}$ Ibidem, 85

${ }^{23}$ Ibidem
} 
pela luta, a necessidade do movimento, o trabalho escolar não é natural: é um artifício criado pela mão humana. Mas é um artifício sobre o qual deverá centrar-se a atenção da criança. Tratar-se-ia, nesse sentido, de desviar e de canalizar o foco da atenção do aluno, de modo que as energias fossem deslocadas para o uso das faculdades mentais e físicas em direção do que, para o autor, seria a educação renovada. Pelas palavras de Faria de Vasconcelos, era a educação nova que se traduziria efetivamente como alternativa contra o fascínio da guerra:

\begin{abstract}
Mas a vida e o trabalho escolar são nas circunstâncias presentes, sobretudo, não apenas uma necessidade fisiológica de equilíbrio nervoso e físico, base de todo desenvolvimento normal e são, mas igualmente um dever sobre o encaminhamento social e humano ao qual é indispensável dirigir a atenção da criança. E se os métodos de ensino e da educação são bem compreendidos, se eles tomam como base os princípios que, há alguns anos inspiram toda a educação nova, a criança se agarrará a eles de uma maneira pronta, viva, tanto quanto as ciências são função da vida social e tanto quanto importa bem conhecê-las para bem utilizá-las como instrumentos poderosos do desenvolvimento humano, de melhoria coletiva e de aprimoramento individual em bondade, em força e em beleza. ${ }^{24}$
\end{abstract}

\title{
A escola como alternativa à guerra
}

Faria de Vasconcelos compreende o ambiente escolar como um ambiente moral. Trata-se, na tradição herdada de Spencer, de, através da escola, formar o sujeito em suas dimensões física, intelectual e moral. Além disso, a escolarização propicia ao estudante adquirir virtudes de personalidade e de sociabilidade: "é necessário que a escola seja um fator ativo, um agente precioso, entranhando a criança pela via do desenvolvimento da individualidade e contribuindo, assim, para sua educação social". ${ }^{25}$ Por outro lado, a guerra como um fato da política permite ver que a escola requer mudanças. Todos esperam transformações após a guerra; inclusive da escola: "que seja permitido aos educadores nutrirem a esperança de que haja muitas transformações no que concerne aos princípios e aos métodos da educação" ${ }^{26}$ Seria preciso, nessa direção, levar as crianças a trabalharem em condições de paz, "com calma, com exatidão, com perseverança em seus estudos. Fazer prova de esforço, de boa vontade, de espírito de continuidade, é afirmar pelos atos uma forte disciplina pessoal, é ensaiar adquirir as qualidades mestras de energia e de vontade que contam na vida". ${ }^{27}$

A ideia era a de que, em tempos de guerra, se os educadores se concentrassem em suas tarefas escolares, os estudantes também o fariam. Estudar - e a criança deveria compreender isso - representaria alargar os horizontes, afinar a sensibilidade, enriquecer-se espiritualmente. Isso significaria sublimar as dores do momento presente, mas reforçar no aluno o sentido do devotamento a um propósito: "dar à criança a ocasião de manifestar os sentimentos de generosidade, bondade, de altruísmo". ${ }^{28}$ Nessa direção,

\footnotetext{
24 Ibidem, 90.

25 Ibidem, 91.

${ }^{26}$ Ibidem

${ }_{27}$ Ibidem

${ }^{28}$ Ibidem, 92.
} 
seria então papel da família e da escola organizar os impulsos e dons da criança, para canalizá-los em direção a um projeto de futuro, que apenas a cultura letrada lhe poderia oferecer. Mas, para além da cultura letrada, a escola significava também o aprendizado de atitudes em relação ao outro, as quais seriam adequadas e requisitadas pela vida social.

\begin{abstract}
A família e a escola devem fazer a criança colaborar de uma maneira regular, consciente, na obra de superação das misérias presentes. 0 melhor meio de estimular na criança os sentimentos de devotamento, de solidariedade e o espírito de sacrifício consiste precisamente em lhe procurar ocasiões apropriadas para exercer, praticar de uma maneira efetiva e real esses sentimentos. Socorrer seus próprios camaradas nas más condições, socorrer os combatentes, socorrer os não-combatentes, são algumas das belas obras nas quais toda criança deve contribuir na proporção de suas possibilidades. $\mathrm{E}$ essa colaboração moral é de natureza a fazer o maior dos bens à criança, se ela for praticada de uma maneira regular e não acidental, ao sabor do acaso e da fantasia, e se a criança souber o que ela faz. ${ }^{29}$
\end{abstract}

A escolarização, de alguma maneira, passa a ser vista aqui como alternativa à guerra. São citadas, sobre o tema, algumas iniciativas de escolas pertencentes a países beligerantes para contribuir com a pacificação do conflito. Crianças norte-americanas, por exemplo, haviam reunido suas economias durante um ano para enviar a seus companheiros dos países em guerra. Outros países faziam as crianças auxiliarem os camaradas feridos e contribuírem com atividades nos hospitais. As meninas eram encarregadas de confeccionar vestimentas para agasalhar os soldados e combatentes. Enfim, havia a intenção de que pudesse ocorrer uma colaboração efetiva das crianças no que eles consideravam ser "a obra de solidariedade humana". ${ }^{30}$

A proposta era a de que cada escola pudesse se organizar de maneira regular e desenvolver com tais iniciativas sentimentos de "devotamento, altruísmo, espírito de sacrifício". ${ }^{31}$ Ou seja, com o pretexto de tirar partido da guerra, estaria sendo desenvolvida a educação moral e social da criança. São mencionadas também algumas iniciativas voltadas para a provisão daquelas pessoas que, estando em situação de carência, não eram, entretanto, combatentes de guerra. Faria de Vasconcelos cita um caso francês, mediante 0 qual, incentivados por uma circular ministerial, os jovens colegiais deveriam contribuir com doações para os trabalhadores que estivessem no desemprego ou mesmo os imigrantes. Tratava-se, nesse sentido, de fomentar a colaboração efetiva e real da criança em um ambiente de solidariedade social, de modo a ensinar e, ao mesmo tempo, levá-la a agir.

A guerra é, ainda, apresentada como "uma admirável lição de coisas, fértil em ensinamentos, em investigação, em trabalhos pessoais, em experiências de todos os gêneros". ${ }^{32}$ A realidade da guerra suscitava para o ensino temas e problemas, comparações e observações. Tirar partido da guerra, do ponto de vista da educação, consistiria em mobilizar o conflito para trabalhar "do mundo físico ao mundo moral, suas repercussões,

\footnotetext{
${ }^{29}$ Ibidem, 92-3.

${ }^{30}$ Ibidem, 96.

${ }^{31}$ Ibidem

32 Ibidem
} 
suas reações, modificações e transformações". ${ }^{33}$ Com a guerra, haveria - continua o texto - coisas horríveis e coisas belas para apresentar à criança. Era como se, no meio do redemoinho da guerra, fosse possível extrair dos fatos um tempo para meditar sobre a justiça, sobre a paz, sobre as relações humanas etc. A partir da guerra, seria possível pensar as questões civis, políticas, industriais, comerciais e econômicas.

\section{Considerações finais: o bom embate e a guerra à guerra}

Faria de Vasconcelos enfatiza a necessidade de declarar guerra à guerra e praticar esse bom combate com as crianças. Além de fomentar - como exposto - as virtudes do devotamento, da solidariedade e do altruísmo, seria imprescindível ensinar aos alunos as virtudes da paz, porque "é fundamental que, após a guerra, a criança guarde em sua memória, em seus olhos, em seu coração, a lembrança real, presente, inapagável, de todos os horrores, de todas as ruínas acumuladas impiedosamente sobre a terra". ${ }^{34} \mathrm{~A}$ ideia era a de que as crianças jamais se esquecessem das monstruosidades da guerra, de maneira a guardar em sua memória todas as vicissitudes daquele momento presente, com a finalidade de construir um futuro de paz; e que daquele momento em diante as pessoas empregassem todos os meios para evitar os conflitos armados. Esse era o objetivo.

$\mathrm{E}$, para isso, o que se deveria fazer? Muitas coisas que nós poderíamos citar em poucas palavras, mas das quais duas, sobretudo, são essenciais à escola: em primeiro lugar, a escola deve se inspirar no mais alto idealismo; a escola atual não educa suficientemente; ela se preocupa em instruir e as considerações de ordem moral e social são preteridas em prol das considerações materiais. Nós vemos apenas um aspecto de preparação para a vida: 0 aspecto exterior, os meios técnicos de ação sobre o meio, e nós deixamos de lado as forças íntimas, as forças humanas, todas as possibilidades, as aptidões morais, físicas do indivíduo. ${ }^{35}$

A cultura geral, o cultivo das ideias, enfim, era preciso aprender tudo que fosse necessário para tornar humano o sujeito a ser formado. Além disso, na criança, deveriam ser incutidas as noções de honestidade e de probidade. Essa seria a forma, não de ensinar um ofício, mas de preparar a paz do futuro.

Princípio fundamental, de aplicação indispensável, que, a par do idealismo criador da humanidade, pode apenas nos livrar dos monstros que devoram nossa civilização, a saber, o militarismo destruidor, o materialismo grosseiro e positivo, o orgulho opressor do nacionalismo imperialista. Assim somente é possível à escola trabalhar em paz na fundação da magnífica cidade humana na qual ninguém poderá dizer que não precisa conhecer a lei, mas que fará sua divisa no respeito à lei, com o fito de que reinem a bondade e a justiça. ${ }^{36}$

Surgia, naquele período, uma sensibilidade nova sobre a situação da infância. Com os adultos podendo ir para a guerra, ou, pelo menos, com esse imaginário social, caberia às crianças um papel muito nítido nas brechas e frestas deixadas na sociedade. O lugar da

\footnotetext{
${ }^{33}$ Ibidem, 97.

${ }^{34}$ Ibidem, 98-9.

35 Ibidem, 99.

${ }^{36}$ Ibidem, 100.
} 
criança, que, na escola se situava na fronteira entre a família e a vida social, em tempos de guerra era deslocado. A guerra chamava a criança para a vida adulta. Era preciso que os educadores dissessem não a esse chamado. Fazer isso, entretanto, significava convocar essa infância para a escola: fosse para resguardá-la, fosse para contribuir para formar 0 combatente do futuro. Esse era o projeto. E essa era a preocupação do educador Faria de Vasconcelos, que, ao dialogar com seu tempo, falava com os tempos por vir. Foi esse cenário, entrelaçado entre as crianças e a guerra, que procuramos reconstituir aqui.

\section{Bibliografia}

Alves, Luís Alberto Marques. "República e educação: dos princípios da Escola Nova ao Manifesto dos Pioneiros da Educação". Revista da Faculdade de Letras - História 11 (2010): 165-180.

Cruz, Maria Gabriel Moreno Bulas. "António de Sena Faria de Vasconcelos (1880-1939): um português no Movimento da Escola Nova”. Educação em Revista 2 (1) (2001): 138-149.

Duarte, Madalena Luzia Pereira. À descoberta da Escola Nova de Faria de Vasconcelos. Dissertação de mestrado, Universidade de Aveiro, 2010.

Fernandes, Rogério. O pensamento pedagógico em Portugal. Lisboa: Instituto da Cultura Portuguesa/Biblioteca Breve, 1978.

Ferreira, António Gomes. "A difusão da escola e a afirmação da sociedade burguesa". Revista Brasileira de História da Educação 5 (1) (2005): 177-197.

Ferreira, António Gomes. "O sentido da educação comparada: uma compreensão sobre a construção de uma identidade”. Educação 31 (2) (2008): 124-138.

Figueira, Manuel Henrique. "A educação nova em Portugal (1882-1935): semelhanças, particularidades e relações com o movimento homónimo internacional (Parte II)". História da Educação 8 (15) (2004): 29-52.

Gomes, Joaquim Ferreira. "A. Faria de Vasconcelos". En Estudos de História e de Pedagogia, 119-140. Coimbra: Almedina, 1984.

Machado, Teresa Sousa. "Faria de Vasconcelos: um pioneiro no movimento da Escola Nova na Europa e na América Latina". Revista Argentina de Ciencias del Comportamiento 8 (2) (2016): 115-123.

Magalhães, Justino. "Intelectuais e história da educação em Portugal e no Brasil". Cadernos de História da Educação 15 (1) (2016): 299-322.

Martins, Ernesto Candeias. "Faria de Vasconcelos, pioneiro da Educação Ativa: orientação escolar e profissional e o sistema educativo português". Imagens da Educação 5 (3) (2015): 70-82.

Meirelles-Coelho, Carlos. "Educação intelectual, moral e física segundo Faria de Vasconcelos". En Actas do Simpósio Internacional Activação do desenvolvimento psicoló- 
gico, 448-453, editores TAVARES, José; PEREIRA, Anabela; FERNANDES, CarIos; MONTEIRO, Sara. Aveiro: Universidade de Aveiro, s/d.

Nóvoa, António. Evidentementemente: histórias da educação. Porto: Asa, 2005.

Ó, Jorge do. "A governamentalidade e a história da escola moderna: outras conexões investigativas". Educação e Realidade 34 (2) (2009): 97-117.

Pintassilgo, Joaquim. "Construção histórica da noção de democratização de ensino: 0 contributo do pensamento pedagógico português". En Democratização escolar: intenções e apropriações, organizado por Maria M. Vieira, Joaquim Pintassilgo and Benedita Melo, 119-141. Lisboa: Centro de Investigação em Educação, 2003.

Vasconcelos, Faria de. Obras completas. Tomo I. Lisboa: Fundação Calouste Gulbenkian, 1986.

Vasconcelos, Faria de. Obras completas. Tomo VII. Lisboa: Fundação Calouste Gulbenkian, 2011 